\title{
Investigation on Temporal and Spatial Distributions of Soil Moisture and Salinity in Typical Subareas of Ningxia Yellow Diversion Irrigation Area
}

\author{
Xinxia GUO ${ }^{\text {a,c }}$, Hefang JING ${ }^{\text {a,b,1 }}$, Weihong WANG ${ }^{\text {a,b }}$ and Wensheng ZHANG ${ }^{\text {a,c }}$ \\ ${ }^{a}$ Research Institute of Numerical Computation and Engineering Applications, North \\ Minzu University, Yinchuan 750021, China \\ ${ }^{\mathrm{b}}$ School of Civil Engineering, North Minzu University, Yinchuan 750021, China \\ ${ }^{\mathrm{c}}$ School of Mathematics and Information Science, North Minzu University, Yinchuan \\ 750021, China
}

\begin{abstract}
The problem of soil salinization in Ningxia Yellow Diversion Irrigation Area is relatively serious, which restricts the sustainable development of agricultural production to some extent. In this paper, the soil moisture and salinity along the West Main Canal and Tanglai Canal in Ningxia Yellow River Irrigation Area are investigated through choosing field sampling, and employing Kriging interpolation method. Soil moisture, salinity ions content and $\mathrm{pH}$ value are measured, and their temporal and spatial distributions are analyzed. The results show that the salinization in the soil surface of the studied area is cohesive and the soil is alkaline. The salinity content in soil gradually increases from southwest to northeast and the soil salination in Nanliang Farm of the studied area is relatively more serious. Generally speaking, the soil moisture along Tanglai Canal is higher than that along West Main Canal.
\end{abstract}

Keywords. Soil moisture, soil salinity, Kriging interpolation, $\mathrm{pH}$ value

\section{Introduction}

According to the incomplete statistics by United Nations Educational Scientific and Cultural Organization(UNESCO) and Food and Agriculture Organization of the United Nations(FAO), there are $9.87 \times 10^{7} \mathrm{hm}^{2}$ saline soil in China, and it mainly exists in Xinjiang Autonomous Region, Hetao Plain, Hexi Corridor, Yinchuan Plain, etc. [1]. In recent years, many research results can be found about soil salination based on Arcgis technology and field sampling and some methods, such as multiple statistical method, principle component analysis, BP neural network and spatial analysis [2-7]. Bai et al. [8] used the classical statistical methods and geostatistics methods to analyze the temporal and spatial variation characteristics of salination in the surface of soil. Wu et al. [9] analyzed the eight salt ions and $\mathrm{pH}$ values along West Main Canal by Pearson correlation analysis and principle component analysis, and drew the spatial distribution

\footnotetext{
${ }^{1}$ Hefang Jing, Research Institute of Numerical Computation and Engineering Applications, North Minzu University, Yinchuan 750021, China; E-mail: jinghef@163.com.
} 
of soil salinity along West Main Canal by Arcgis software. Li et al. [10] chose Yongji irrigation area in Hetao as the research area, obtained the probability distribution of salinity content in the topsoil, burial depth and mineralization of groundwater under different thresholds. Onkware et al. [11] explored the spatial variability of soil salinity at different depths by using the variation function. Akramkhanov et al. [12] simulated the spatial distribution of soil salinity content in a high irrigation landscape based on environmental predictors. Du et al. [13] applied statistical methods and common Kriging methods to reveal the annual spatial and temporal distribution law of groundwater burial depth and mineralization in the Hetao irrigation area in Inner Mongolia. In order to understand the degree of soil salinization in Tianjin Plain, Jia et al. [14] carried out a sampling survey of soil salinity content outside the embankment along three rivers and analyzed the spatial gradient and variation characteristics of soil salinity.

The above research results have important theoretical and engineering values in soil salinization monitoring. However, a few research results can be found about termperal and spacial distribution and variation of soil moisture and salinity in Yellow Diversion Irrigation Area in Ningxia, China. In this study, based on Arcgis technology, the spatial and temporal distribution characteristics of water and salt in soil in Ningxia Yellow Diversion Irrigation Area are analyzed.

\section{Methodology}

\subsection{The Studied Area}

In order to study the soil moisture and salinity in Ningxia Yellow Diversion Irrigation Area, we chose farms and cultivated lands along West Main Canal and Tanglai Canal for field sampling. The studied area is located in the northwest of Ningxia Hui Autonomous Region with Helan Mountain in its west, as shown by figure 1 . The longitudinal and latitude of the studied area are from $105^{\circ} 57^{\prime} \mathrm{E}$ to $106^{\circ} 31^{\prime} \mathrm{E}$ and from $37^{\circ} 55^{\prime} \mathrm{N}$ to $38^{\circ} 52^{\prime} \mathrm{N}$, respectively. The average annual precipitation is $176 \mathrm{~mm}$, but the average annual evaporation volume is $1755 \mathrm{~mm}$ [15]. Some of the field sampling points are sprinkled in typical farms, such as Nuanquan Farm, Nanliang Farm, Helan Mountain Farm, Pingjipu Farm, Huangyangtan Farm, etc. The cultivated lands in the studied area take water from West Main Canal or Tanglai Canal for irrigation, and the two canals transport water from the Yellow River. Because of the charateristics of high in the north and the higher in the south, and higher sediment concentration in the Yellow River, the soil moisture and salinity distribution in the studied area are different from other places.

\subsection{Research Methods}

\subsubsection{Typical Sampling Point Selection}

92 sampling points along Tanglai Canal and 73 sampling points along the West Main Canal are set by using GPS, and the total number of field sampling point is 165 , in which 9 at Nanliang Farm, 11 at Nuanquan Farm, 20 at Helan Mountain Farm, 17 at Pingjipu Farm and 16 at Huangyangtan Farm, as shown in figure 1. 


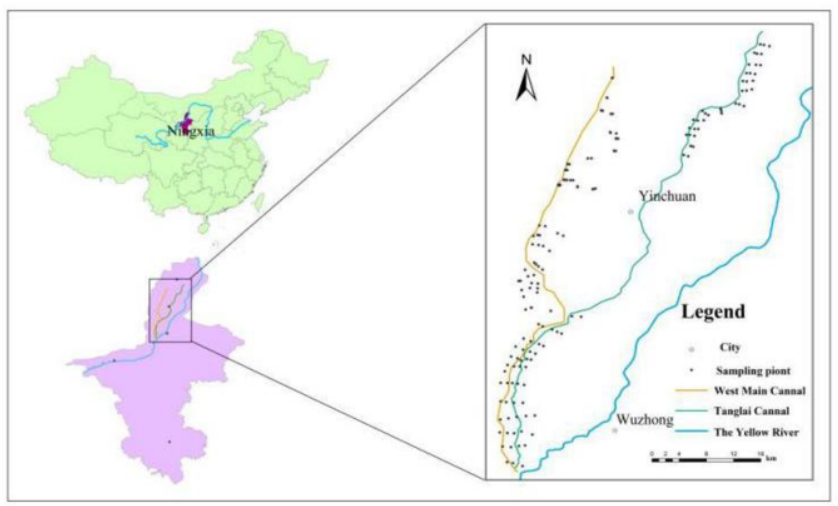

Figure 1. Distribution of sampling points.

\subsubsection{Soil Sample Collection}

Soil samples were collected from August 2019 to December 2020 to measure the soil moisture, salinity and $\mathrm{pH}$ value in the studied area.

About 45 cross sections were set along West Main Canal and Tanglai Canal in the research area, and 2-5 sampling points are selected for each cross section. At a few sampling points, the soil was divided inyo 5 layers: $0-20 \mathrm{~cm}, 20-40 \mathrm{~cm}, 40-60 \mathrm{~cm}, 60-$ $80 \mathrm{~cm}, 80-100 \mathrm{~cm}$. However, at most of sampling points, the soil was divided into 2 layers: $0-20 \mathrm{~cm}, 20-40 \mathrm{~cm}$. The soil samples were picked up using soil sampler, placed into plastic self-sealing bags and then brought back to the laboratory to measure. The soil moisture was measured by drying method, and soil particle size distribution was measured by laser particle size analyzer. The salt ions, such as $\mathrm{Ca}^{2+}, \mathrm{Mg}^{2+}, \mathrm{SO}_{4}{ }^{2-}$, $\mathrm{HCO}_{3}{ }^{-}, \mathrm{CI}^{-}, \mathrm{Na}^{+}, \mathrm{K}^{+}$, and $\mathrm{pH}$ value were measured by a professional testing center.

\subsubsection{Kriging Interpolation Method}

The Kriging interpolation method is a regression algorithm for spatial modeling and interpolation of random processes/random fields in terms of the covariance function. In specific stochastic processes, such as intrinsic stationary processes, the method can give best linear unbiased prediction (BLUP), hence the Kriging interpolation is also known as spatial BLUP [16] in geostatistics.

\section{Result and Analysis}

\subsection{Statistical Analysis of Salinity Ions and pH Values in Soil}

Statistical analysis is conducted for the salt ions and $\mathrm{pH}$ value of the samples in the studied area, as shown in table 1 . The average $\mathrm{pH}$ value of soil is 8.4 , indicating that the soil in this area is alkaline. The soil total salinity is the sum of the various salinity ions in the soil solution to show the level of soil salinization. The average value of soil total salinity is $2.75 \mathrm{~g} / \mathrm{kg}$, with the maximum of $13.21 \mathrm{~g} / \mathrm{kg}$ and the minimum of $0.44 \mathrm{~g} / \mathrm{kg}$. According to the salinized soil classification standard in China, most of the soil in the research area usually belongs to the moderate salinized soil. 
Table 1. Statistical characteristics of ions content, total salinity and $\mathrm{pH}$ value.

\begin{tabular}{lllllllllll}
\hline Project & $\begin{array}{l}\text { Average } \\
\text { value }\end{array}$ & Median & $\begin{array}{l}\text { Standard } \\
\text { deviation }\end{array}$ & $\begin{array}{l}\text { Skew- } \\
\text { ness }\end{array}$ & Kurtosis & Min & Max & \multicolumn{3}{c}{$\begin{array}{l}\text { Coefficie } \\
\text { nt of } \\
\text { variation }\end{array}$} \\
\hline $\mathrm{pH}$ & 8.4649 & 8.5100 & 0.3747 & -0.6770 & 0.3850 & 7.1000 & 9.1400 & 0.0443 & 0.0450 \\
$\mathrm{CO}_{3}{ }^{2-}$ & 0.0283 & 0.0260 & 0.0279 & 2.5910 & 12.8490 & 0.0000 & 0.2112 & 0.9849 & 0.0000 \\
$\mathrm{HCO}_{3}{ }^{-}$ & 0.5832 & 0.3800 & 0.6138 & 4.1610 & 26.0640 & 0.0305 & 5.8700 & 1.0525 & 0.0000 \\
$\mathrm{Cl}^{-}$ & 0.2558 & 0.1523 & 0.3906 & 5.7730 & 46.1600 & 0.0183 & 4.1400 & 1.5269 & 0.0000 \\
$\mathrm{SO}_{4}{ }^{2-}$ & 1.0396 & 0.7379 & 1.0169 & 2.8200 & 12.5240 & 0.0200 & 8.2300 & 0.9781 & 0.0000 \\
$\mathrm{Ca}^{2+}$ & 0.4164 & 0.2230 & 0.5709 & 3.3030 & 11.0120 & 0.0600 & 3.0800 & 1.3711 & 0.0000 \\
$\mathrm{Mg}^{2+}$ & 0.1324 & 0.0900 & 0.1295 & 2.4650 & 7.5310 & 0.0099 & 0.8700 & 0.9780 & 0.0000 \\
$\mathrm{Na}^{+}$ & 0.2530 & 0.1067 & 0.4550 & 4.0960 & 19.0290 & 0.0100 & 3.0400 & 1.7987 & 0.0000 \\
$\mathrm{~K}^{+}$ & 0.0417 & 0.0290 & 0.0456 & 3.3790 & 14.2430 & 0.0036 & 0.3340 & 1.0951 & 0.0000 \\
$\mathrm{Total}_{\text {salinity }}$ & 2.7504 & 2.1155 & 2.0374 & 2.0500 & 5.1760 & 0.4420 & 13.2080 & 0.7408 & 0.0000 \\
\hline
\end{tabular}

It can be seen from table 1, the subsequence from great to little for the average content of soil salt anions in the studied area is $\mathrm{SO}_{4}{ }^{2-}, \mathrm{HCO}_{3}{ }^{-}, \mathrm{Cl}^{-}$, and $\mathrm{CO}_{3}{ }^{2-}$; the subsequence from great to little for the average content of salt cation is $\mathrm{Ca}^{2+}, \mathrm{Na}^{+}$, $\mathrm{Mg}^{2+}$ and $\mathrm{K}^{+}$; the basic anion is mainly $\mathrm{SO}_{4}{ }^{2-}$ the basic cation is mainly $\mathrm{Ca}^{2+}$, and the main type of salt is sulfate.

Kolmogorov-Smirnov(K-S) Test can detect whether the sample is generally subject to a distribution. In this paper, K-S test is employed to determine whether the $\mathrm{pH}$ value, salt ion contents and total salt content obey normal distribution. It is generally acknowledged that it is normal distribution if the test value $\mathrm{P}$ is larger than 0.05 , otherwise it is non-normal distribution. According to K-S test of salt factor and $\mathrm{pH}$ value in soil, all of the test values of $\mathrm{pH}$ value and salt ions in soil are less than 0.05 , which indicate that $\mathrm{pH}$ value and salt ions do not obey normal distribution.

The coefficient of variation $(\mathrm{CV})$ reflects the degree of discretization of random variables. Generally considering, it is weak variability when $\mathrm{CV}$ is less than or equal to 0.1 ; it is moderate variability when $\mathrm{CV}$ is larger than 0.1 and less than 1 , and it is strong variability when $\mathrm{CV}$ is larger than or equal to 1 . The coefficient of variation reflects the spatial variation strength of the soil salinity content. In the study area, CVs of salinity ions $\mathrm{HCO}_{3}^{-}, \mathrm{Cl}^{-}, \mathrm{Ca}^{2+}, \mathrm{Na}^{+}$and $\mathrm{K}^{+}$are larger than 1 , indicating they are strong varied, their spatial distribution are uneven, and their change rate is large; CVs of salinity ions $\mathrm{CO}_{3}{ }^{2-}, \mathrm{SO}_{4}{ }^{2-}, \mathrm{Mg}^{2+}$ and total salinity are larger than 0.1 and less than 1 , indicating they are moderate varied; $\mathrm{CV}$ of $\mathrm{pH}$ value is less than 0.1 , indicating it is weak varied its spatial distribution is uniform and its change rate is small.

\subsection{Spatial Distribution of Soil Salinity and $\mathrm{pH}$ Value}

Based on the measured data of soil salinity, $\mathrm{pH}$ value and salt ions' content, the Kriging interpolation method is employed to obtain their spatial distributions, as shown in figure 2 . 


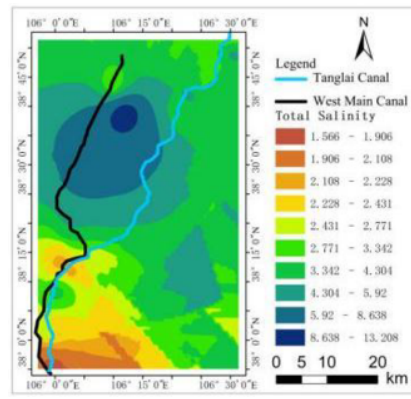

(a) total salinity.

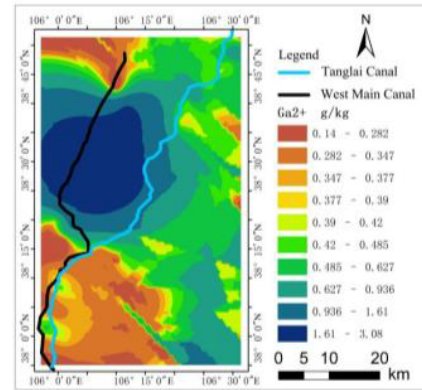

(c) $\mathrm{Ca}^{2+}$.

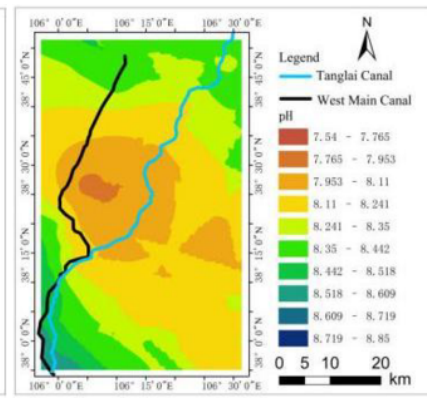

(b) $\mathrm{pH}$ value.

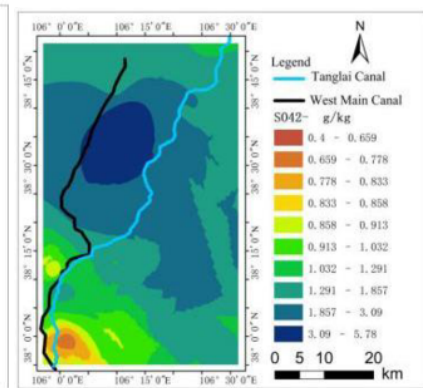

(d) $\mathrm{SO}_{4}{ }^{2-}$

Figure 2. Spatial distributions of soil salinity content and $\mathrm{pH}$ value.

It can be found in figure 2 that the total soil salinity is gradually increasing from southwest to northeast, and heavy salinized soil appears near the position between West Main Canal and Tanglai Canal .It can also be found that all of the soil in the research area is alkaline and the soil is the very alkaline near Lixin Township and Dam Town. The spatial distribution of $\mathrm{Ca}^{2+}$ is characterized by high in the north and the south, and low in the center. In Huangyangtan Farm, the $\mathrm{Ca}^{2+}$ content is the highest. Similar to $\mathrm{Ca}^{2+}$, the maximum of $\mathrm{SO}_{4}^{2-}$ content is also distributed in the north of Minning Town, showing the increasing trend along West Main Canal and Tanglai Canal from south to north.

\subsection{Spatial Distribution of Soil Moisture}

Based on the field measurd data of soil moisture, Kriging Interpolation Method is employed to obtain the spatial distribution of moisture. As shown in figure 3, the spatial distribution of soil moisture along the West Main Canal is lower than that along Tanglai Canal. Near the northern Jinshan Township and central Minning Town, where the average moisture content is between $5 \%$ and $9 \%$. It can also be found that the average soil moisture content is high near the main canals of the Tanglai Canal and West Main Canal and it is low far away from the main canals. 


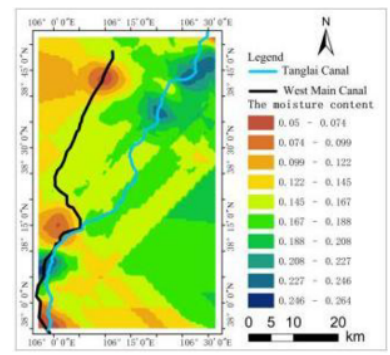

Figure 3. Spatial distribution of soil moisture content.

\subsection{Temporal Distribution of Soil Moisture}

Water is the carrier of soil salinity, and water movement is the main cause of salt accumulation and the power of soil desalination. In order to study the migration of salinity content between farmland and wasteland, it is neccessary to understand the movement law of water. In 2020, in order to further study the water balance in farmland, five times moisture content of field samples are chosen to study the water movement of the studied area.

The samples in Nanliang Farm and Pingjipu Farm where soil salinization is relatively serious are analyzed, as shown in figures 4 and 5 . It can be seen that the moisture content change trends of the five soil layers in Nanliang Farm are similar. The moisture content is the lowest in August 2020, while it is high in June and September 2020 in Nanliang Farm. In Pingjipu Farm, the moisture content is low in August and October, while it is high in June and September 2020.

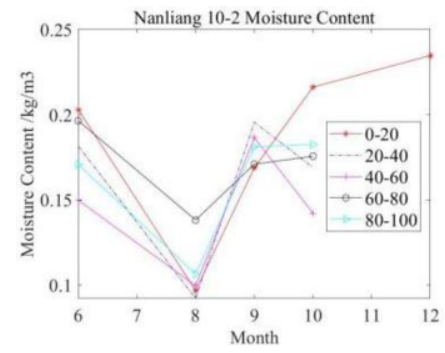

Figure 4. Moisture content variation of five soil layers in Nanliang Farm in 2020.

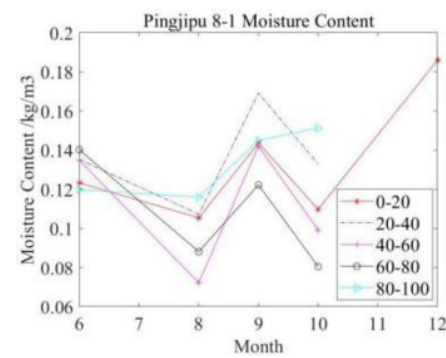

Figure 5. Moisture content variation of five soil layers in Pingjipu Farm in 2020.

\subsection{Temporal Distribution of Soil Salinity}

The full salinity content variations in Nanliang Farm and Pingjipu Farm in 2020 are shown in figures 6 and 7. Comparison among the total salinity of different layers, it can be concluded that the total salinity decreases from the soil surface to the deep layer, and its change rate near the surface soil layer is larger than that near the deep soil layer. The soil salinity content increases from June to September 2020 and then decreases in Nanliang Farm, while it inceases fast from June to August and then it increases slow or decreases. From the comparison of the two farms, the total salinity content of Nanliang Farm is higher than that of Pingjipu Farm. 


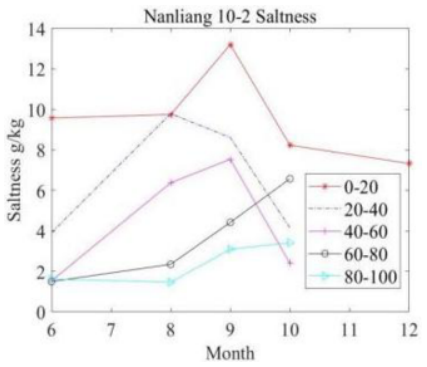

Figure 6. Total salinity ariation of five soil layers in Nanliang Farm in 2020.

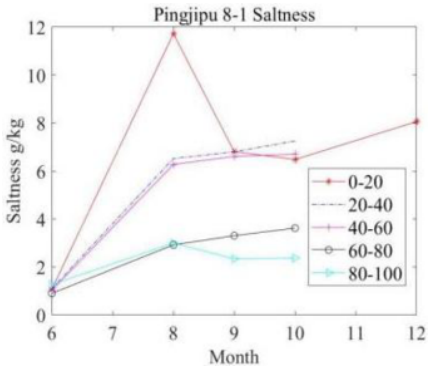

Figure 7. Total salinity ariation of five soil layers in Pingjipu Farm in 2020.

\section{Conclusion}

In this study, some typical subareas in Ningxia Yellow River irrigation area are chosen for research the temporal and spatial distribution characteristics of the soil salinity, $\mathrm{pH}$ value and moisture content .The main research results are as follows:

(1) Statistical analysis is conducted for the salt ions and $\mathrm{pH}$ value of the samples in the studied area. In the studied area, all the soil is alkaline, and most of the soil belongs to the moderate salinized soil.

(2) It can be seen from table 1, the subsequence from great to little for the average content of soil salt anions in the studied area is $\mathrm{SO}_{4}{ }^{2-}, \mathrm{HCO}_{3}{ }^{-}, \mathrm{Cl}^{-}$and $\mathrm{CO}_{3}{ }^{2-}$; the subsequence from great to little for the average content of salt cation is $\mathrm{Ca}^{2+}, \mathrm{Na}^{+}$, $\mathrm{Mg}^{2+}$ and $\mathrm{K}^{+}$; the basic anion is mainly $\mathrm{SO}_{4}{ }^{2-}$ the basic cation is mainly $\mathrm{Ca}^{2+}$, and the main type of salt is sulfate.

(3) According to K-S test of salt factor and $\mathrm{pH}$ value in soil, all of the test values of $\mathrm{pH}$ value and salt ions in soil are less than 0.05 , which indicate that $\mathrm{pH}$ value and salt ions do not obey normal distribution.

(4) In the study area, $\mathrm{HCO}_{3}^{-}, \mathrm{Cl}^{-}, \mathrm{Ca}^{2+}, \mathrm{Na}^{+}$and $\mathrm{K}^{+}$are strong varied, while $\mathrm{CO}_{3}{ }^{2-}$, $\mathrm{SO}_{4}{ }^{2-}, \mathrm{Mg}^{2+}$ and total salinity are moderate varied, and $\mathrm{pH}$ value is weak varied. The total soil salinity is gradually increasing from southwest to northeast.

(5) In Nanliang Farm, the moisture content is the lowest in August 2020, while it is high in June and September 2020. In Pingjipu Farm, the moisture content is low in August and October, while it is high in June and September 2020.

(6) The average soil moisture content is high near the main canals of the Tanglai Canal and West Main Canal and it is low far away from the main canals.

(7) The total salinity decreases from the soil surface to the deep layer, and its change rate near the surface soil layer is larger than that near the deep soil layer. The soil total salinity content increases from June to September 2020 and then decreases in Nanliang Farm, while it inceases fast from June to August and then it increases slow or decreases.

\section{Acknowledgments}

The authors gratefully acknowledge the support of the following projects: the Funds of National Natural Science Foundation of China (grant number: 11861003 and 
11761005); the Project of Key Research and Development Planned by Science and Technology Department of Ningxia, China (grant number:2019BEG03048).

\section{References}

[1] Gebremeskel G, Gebremicael TG, Kifle M, et al. Salinization pattern and its spatial distribution in the irrigated agriculture of Northern Ethiopia: An integrated approach of quantitative and spatial analysis. Agricultural Water Management. 2018 Jul; 206: 147-57.

[2] Yang F, An FH, Ma HY, et al. Spatial variation of soil apparent electrical conductivity of soda salinated dry field in Songen Plain. Acta Ecol. Sin. 2017 Feb; 37(4): 1184-1190.

[3] Yao RJ, Yang JS, Liu GM, et al.Study on soil salinity spatial variation of typical plots in Yellow River Delta Transactions of the CSAE. 2006 Jun; 2(6): 61-66.

[4] Fan LQ, Yang JG, Xu X, et al.Salinity characteristics and correlation of saline-alkali soil in Ningxia Yellow Diversion Irrigation Area. Chinese Agricultural Science Bulletin. 2012 Dec; 28(35): 221-225.

[5] Ordan MM, Navarro PJ, Garcia SE, et al.Spatial dynamics of soil salinity under arid and semi-arid conditions: geological and environmental implications. Environmental Geology. 2004 Feb; 45(4) : 448456.

[6] Wang YG, Deng CY, Liu Y, Liu Y,et al.Identifying change in spatial accumulation of soil salinity in an inland river watershed. China.Science of the Total Environment. 2018 Apr; 621: 177-85.

[7] Yang F, Zhang GX, Yin XR, et al.Fieldscale spatial variation of salinesodic soil and its relation with environmental factors in west-ern Songnen plain of China. International Journal of Environmental Research and Public Health. 2011 Feb; 8(2): 374-387.

[8] Bai JD, Peng J, Bai ZJ, et al.Study on temporal and spatial variation of surface soil salinization in cotton field in arid area. Chinese Journal of Soil Science. 2021 Jun; (03): 527-534.

[9] Wu JT, Jing HF, et al.Investigation of the Salinity Distribution of the Soil along West Main Canal in Ningxia,China. IOP Conference Series: Earth and Environmental Science. 2021 Mar: 012012.

[10] Li XY, Cui JQ, Shi HB, Sun YN, et al. Risk of soil salinization and groundwater environmental analysis based on indicative kriging. Journal of Agricultural Machinery. 2021 May; 35: 1-11.

[11] Augustino OO. Effect of soil salinity on plant distribution and production at Loburu delta; Lake Bogoria National Reserve; Kenya. Austral Ecology. 2000 Apr; 25(2): 140-149.

[12] Akramkhanov A, Martius C, Park SJ, et al. Environmental factors of spatial distribution of soil salinity on flat irrigated terrain .Geoderma. $2011 \mathrm{Jun}$; 163(1): 55-62.

[13] Du J, Yang PL, Li YK, et al.Space and temporal changes of groundwater burial depth and mineralization in Hetao irrigation area. Transactions of the CSAE. $2010 \mathrm{Jul}$; 26(07): 26-31+391.

[14] Jia J, He P, Xu J, et al. Analysis of space distribution of soil salinity in central and eastern plain of Tianjin. Journal of Environmental Engineering Technology. 2021 Mar; 1-10: 06-10.

[15] Mi WB, Liu XP. Research on the regional system of man-land relationship in Ningxia Yinchuan. Ningxia People's Publishing House. 2009 Feb; 2: 220-228.

[16] Lei C, Wang HQ, Fei T, et al. Crekin interpolation method based on multiscale least squares support vector machine optimization. Journal of Geo-Information Science. 2017 Aug; 19(08): 1001-1010. 